\title{
ATTACKS OF VESPA COMMUNIS DE SAUSSURE ON HYPHANTRIA CUNEA DRURY.
}

\section{By M. T. Smulyan.}

U. S. Bureau of Entomology, Melrose Highlands, Mass.

The wasp attacks reported here occured during September 1923 , at Roycefield, N. J., and were made on fall webworm larvæ (Hyphantria cunea Drury) which had been collected in a number of localities for parasite study purposes. The wasps (Vespa communis De Saussure) ${ }^{1}$ appeared, suddenly and in large numbers, as the first collection of the webworms was being examined out of doors, and they literally threw themselves upon the caterpillars, and their attacks were so persistent and savage that all efforts to drive them off, although it resulted in the death of many of them, were fruitless. The attacks began very early in the month, and they were continued at intervalsin connection with each out of door examination of the webworms-throughout the ten-day collecting period. Attacks upon the caterpillars were made also while they were in a more or less open, near-by shelter, where they had been placed in rearing trays, and the wasps exhibited the same degree of ferocity and voracity here. They attacked here not only at the feeding of the caterpillars, when the trays were uncovered, but throughout the greater part of the day-through the screen coverswhenever caterpillars appeared on the undersides of the latter; and they continued this, although in decreasing numbers, until the last week of September when following a two or three day period of cold weather they disappeared altogether.

The wasps, it should be added, apparently made no at tempts to carry off the caterpillars. Nor, as far as could be seen, did they malax them. They would precipitate themselves upon them. pierce the integument with their mandibles, and consume the liquid and softer parts.

${ }^{1}$ Determined by Dr. J. Bequaert of the Harvard University Medical School, on the return of the writer to Melrose Highlands, Mass. 
The wasps were not seen to attack insects prior to the attacks reported here, although individual workers were observed from time to time in the vicinity throughout the summer. But very likely they were at those times merely seeking food of vegetable character. The fondness of adult wasps for this type of food is well known of course, and their indifference to animal food at times of the abundance of the former has been noted.

The behavior of the wasps-aside from their apparent failure to carry off or to malaxate the caterpillars-may probably be explained on the ground of a shortage or dearth of food-both plant and animal-because of the lateness and dryness of the season; the summer of 1923 was exceedingly dry in New Jersey. The suggestion (which has been made) that the wasps' ferocity and rapid consumption of the liquid portions of the caterpillars were perhaps due to a desire for water-the fondness or need of wasps for water is also well known-is hardly satisfactory. First, there was available the water from the heavy dews; secondly, the wasps continued to seek the caterpillars in the rearing trays in the shelter, although in smaller numbers, during a two-day rain-storm. It was hunger, eivdently, rather than thirst which influenced the wasps.

The exact location of the wasp nest was not discovered. 

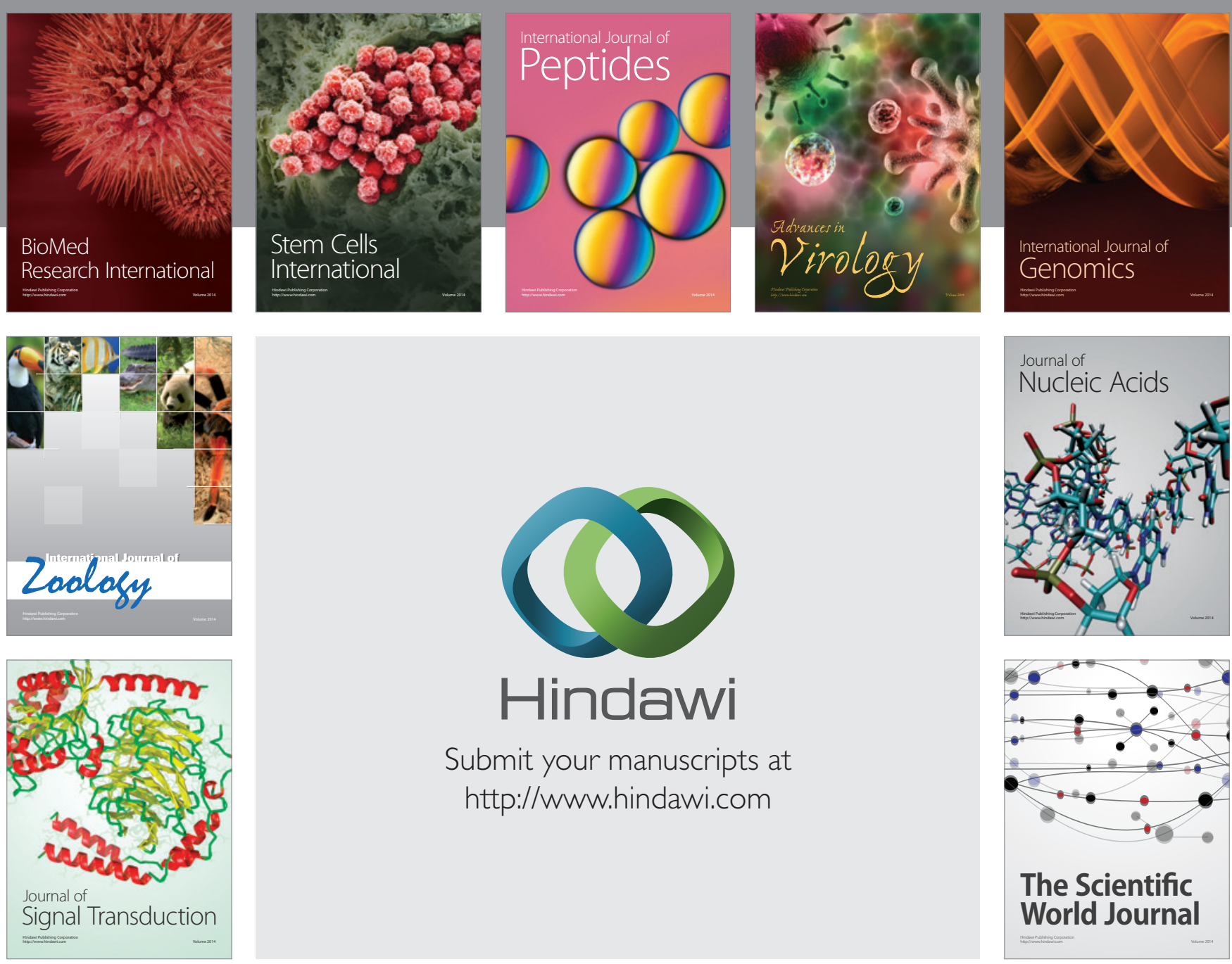

Submit your manuscripts at

http://www.hindawi.com
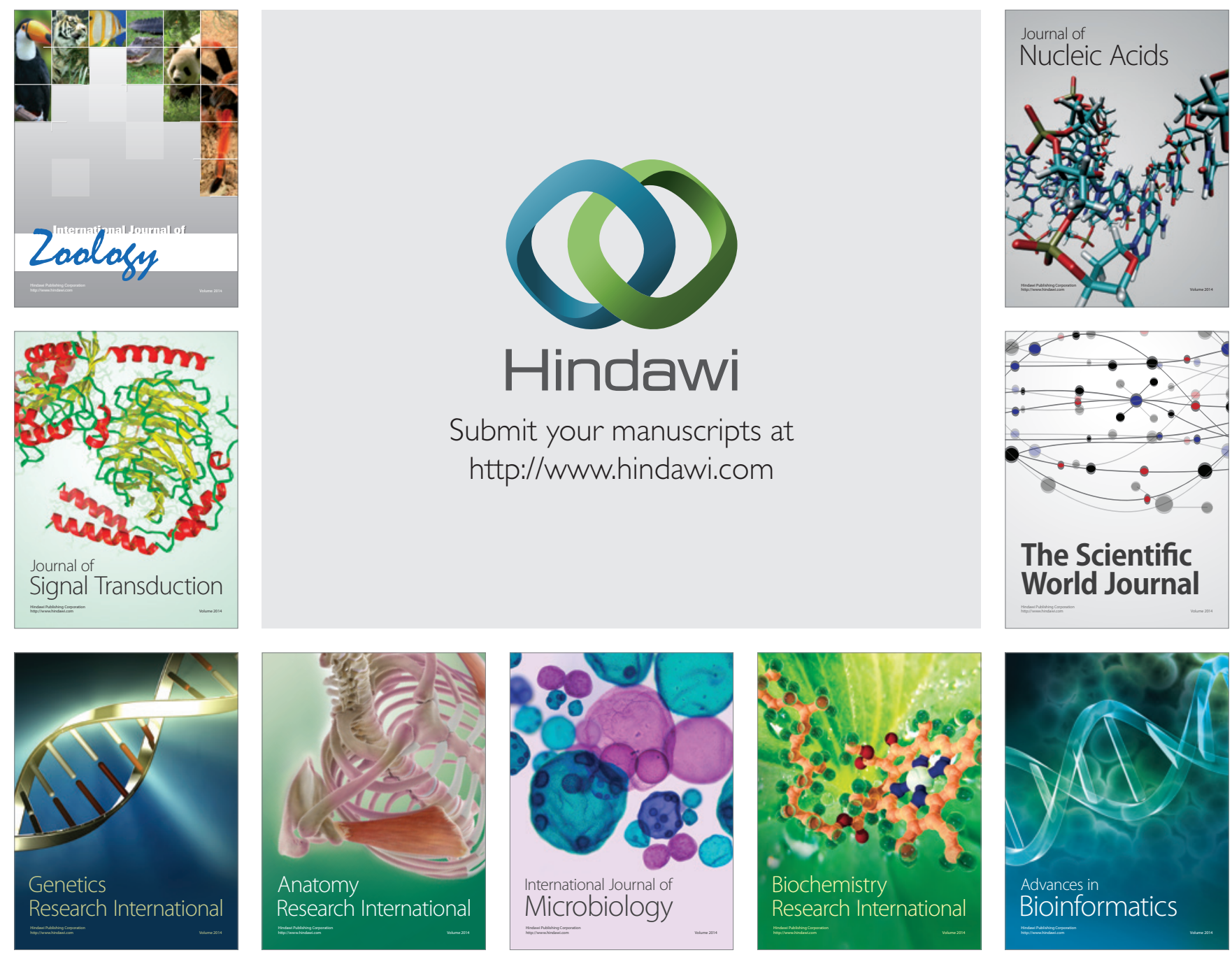

The Scientific World Journal
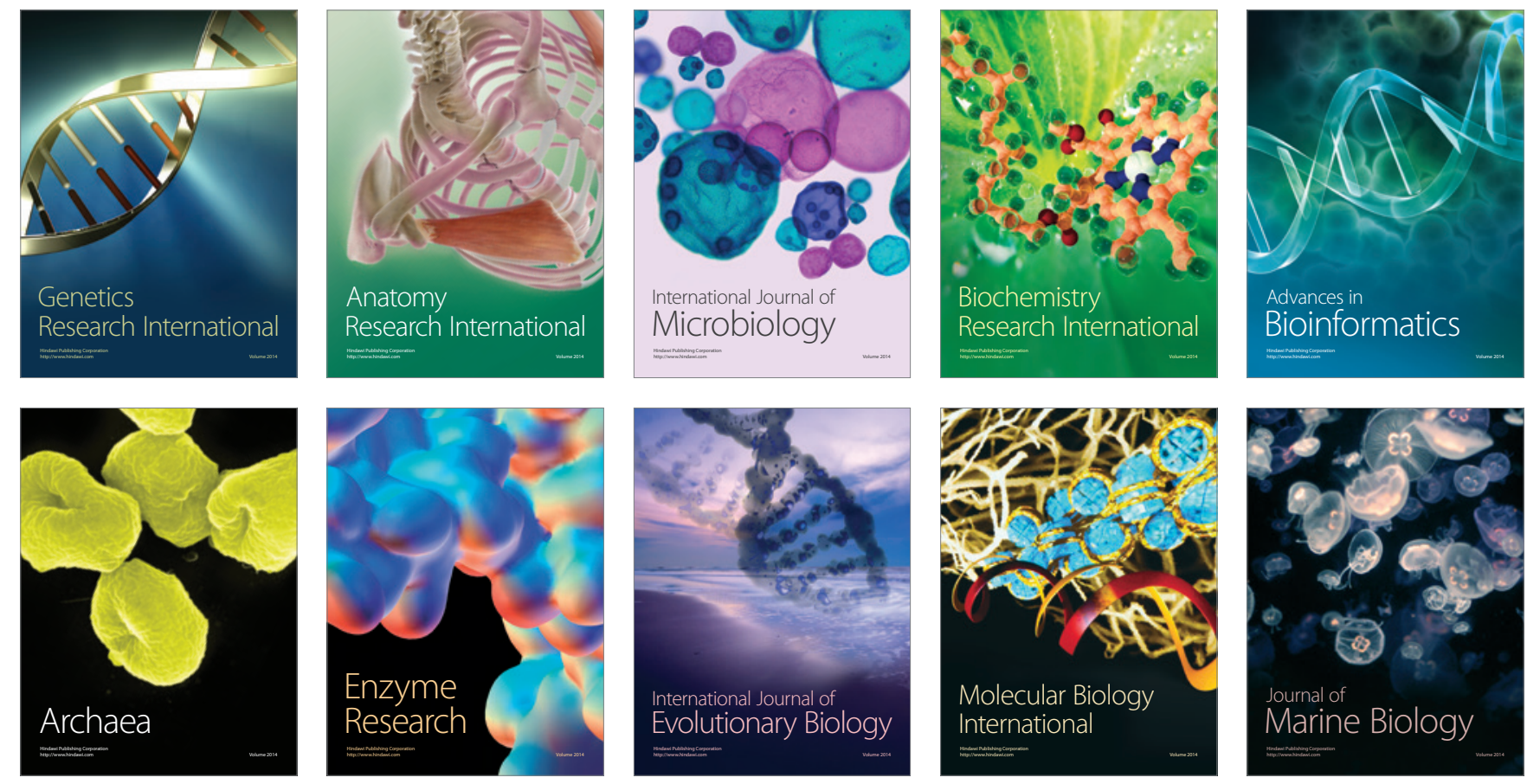